\title{
Permanent Modular Construction: construction performance
}

\author{
Ryan E. Smith ${ }^{1}$ and Talbot Rice ${ }^{2}$ \\ ${ }^{1}$ Associate Professor, Director, Integrated Technology in Architecture Center, College of \\ Architecture + Planning (ITAC), University of Utah \\ ${ }^{2}$ Research Associate, ITAC, University of Utah \\ Corresponding author's e-mail: rsmith@arch.utah.edu
}

\begin{abstract}
This paper reports on a portion of a study to determine the construction performance of permanent modular construction (PMC) with the goal to verify industry claims of cost and schedule. The research uses a test bed of international PMC case studies. The PMC projects recorded provide a sample to evaluate the performance metrics attributed to off-site construction. The study finds that PMC project samples were $11 \%$ more cost effective and $42 \%$ improved schedule performance when compared to traditional site built projects.
\end{abstract}

\section{KEYWORDS}

permanent modular construction (PMC), construction performance, case study method

\section{INTRODUCTION}

PMC has been marketed as more cost effective, higher quality, and a faster to market solution than traditional stick built construction. (MBI) The added value of PMC, although conceptually strong, has yet to be significantly substantiated. This research aims to provide data to fill this data gap. The study quantifies the added value of PMC and evaluates the contextual factors by which PMC in building design and construction may be realized in North America and beyond. The research leverages 17 case studies listed in Table 1 and compares a portion of them to traditional site build benchmark projects for performance parameters include cost and schedule. The data was collected through literature review, questionnaire, and interviews.

\section{METHODS}

\section{Case Study Method}

This study utilizes case study method for investigation. Case study is a common strategy in built environment research by which completed project data is collected and analyzed for generalizable results. The case study project pool was established in consultation with the Modular Building Institute Foundations and the National Institute of Building Sciences Off-site Construction Council. The decision of 17 cases documented was based on:

- access to available archival data and willingness of the stakeholders to participate and offer additional data;

- diversity of project sizes, locations and building types in order to evaluate PMC across sectors, countries and cultures; and 
- architecturally significant buildings to demonstrate how PMC performance with respect to buildings that have a greater opportunity for continued cultural investment.

A ranking system considering these 3 factors was devised and provided a rudimentary process for determining the final list. Data was gathered from the architect, general contractor/construction manager, and the modular manufacturer/supplier for the respective projects. In projects in which there was not a response from all three parties, at least two were consulted. A questionnaire was developed and peer review edited to identify the quantitative data including cost and schedule. This was disseminated online and through PDF response form. Reponses were limited and therefore follow up interviews were conducted to gather additional and clarifying metric data and perform qualitative interviews. Limited forthcoming data led to exclusion of some cases in portions of the study. In total, there are 10 cases among the 17 that have substantial cost and schedule information. From these 10 cases, 7 of them could be compared in schedule, and 8 in cost to traditional stick built construction benchmark projects.

Table 1. Case study projects and their geographic location.

\begin{tabular}{|cc|}
\hline PROJECT & LOCATION \\
\hline Xstrata Nickel Rim South & Greater Sudbury, Ontario, Canada \\
\hline High Tech High & Chula Vista, CA, USA \\
SOMA Studios & San Francisco, CA, USA \\
\hline STEM School & Redmond, WA, USA \\
Nicholson Village & Melbourne, Australia \\
\hline Old Redford Academy & Detroit, MI, USA \\
\hline MEG Pirate's Cove Lodge & Conklin, Alberta, Canada \\
\hline CitizenM Bankside & London, England \\
\hline Mercy Hospital & Joplin, MO, USA \\
\hline Starbucks & Marysville, WA, USA \\
\hline Victoria Hall Wolverhampton & Wolverhampton, England \\
Whistler Athletes Lodge & Whistler, BC, Canada \\
\hline Inwood Apartments “The Stack" & New York City, New York \\
\hline Manresa Student Housing & Manresa, Spain \\
Wells Fargo & Phoenix, AZ, USA \\
\hline Kirkham Child Care Center & San Francisco, CA, USA \\
The Modules & Philadelphia, PA, USA \\
\hline
\end{tabular}

\section{Comparative Method}

The data from the PMC projects was compared to benchmark projects developed by Cumming Corp, a cost consultancy firm. Key parameters in developing these benchmark comparisons include:

- Data for both the PMC cases and traditional benchmark comparisons cases have been normalized to first quarter 2014 in US Dollars and Washington DC as the building location. 
- Units of cost are calculated in $\$ / \mathrm{SF}$ and it is assumed that all of the benchmark projects use a design-bid-build delivery system. When possible, estimates for the comparisons are based on actual items of work. When data was not available, precedent values from other projects have been interpolated for these comparative projects.

- Unit costs are based on current bid prices in Washington DC and subcontractor overhead and mark-ups have been included. General contractor overhead and profit has been excluded.

- The values determined were based on the probability of cost of construction at the programmatic design stage.

For estimating the values to construct the benchmarks, the following sources have been referenced: David Bacon Wage Rates, RS Means Geographical Indices, RS Means Standard Hourly Rates for Construction Industry, and Cumming Corp Internal Economic and Market Report. The items not covered in this comparative include: hazardous material abatement, utility infrastructure improvements, design/consulting fees, building permits, testing and inspection fees, and land acquisition costs.

\section{Limitations}

There were limitations realized during this study. The first limitation is the fact that there are few PMC cases to date that are built relative to traditional construction. The ability to quantify a trend or make a statistical argument is difficult without more cases. Furthermore, the amount of information that was provided for particular projects by stakeholders was limited as well. More often than not, items such as the cost information and labor hours where not shared by participants. With the small amount of information on the already minimal amount of case studies, there is a challenge in the ability to report statically significant results. However, these cases provide timely evidence of project specific performance.

\section{RESULTS}

\section{Cost}

The cost of PMC has claimed to be less expensive compared to traditional methods of construction. Further analysis in these cases demonstrates that cost is not necessarily always less. In fact, the cost sometimes comes a premium. The study overall suggests that PMC projects are on average $11 \%$ lower in vertical construction cost compared to conventional methods of construction. (Fig. 1)

It is important to note that stakeholders reported PMC offers a higher control of cost compared to traditional build. This is attributed to the inherent ability to reduce the number of change orders in any given PMC project. In a recent study conducted in Montgomery County, Maryland, the Office of Legislative Oversight studied 17 county government projects that reached substantial completion between 2009-2013. The study found an $8 \%$ overall increase in contract costs due to change orders. Respondents concluded that the reason why modular construction is cost controlled is because the design must be near complete before modular production, driving change orders down. 
COST PER SQUARE FOOT COMPARISON

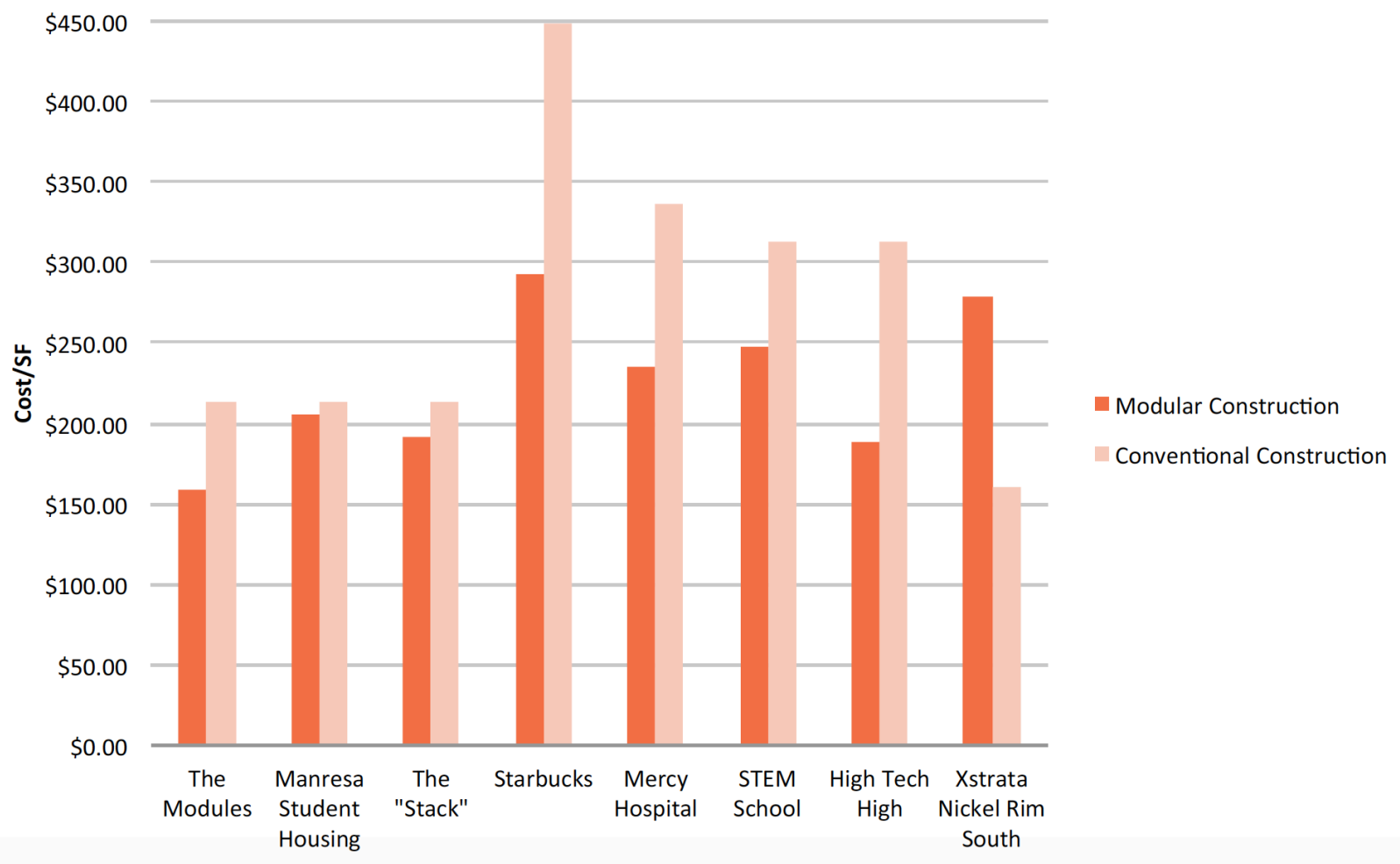

Figure 1. Cost of PMC vertical construction compared to benchmark projects.

When cost was a premium, respondents listed the following reasons:

- additional materials required for structure and transport;

- transportation costs for large load permits and lead cars;

- time lost due to permitting;

- time lost due to transportation of long distances.

\section{Schedule}

Schedule reduction is a claim the industry has demonstrated is a clear advantage to PMC in precedent research. (Smith, 2011) Across the case studies documented, schedule was reduced by an average of $42 \%$. (Fig. 2 ) Respondents indicated that this is due to the fact that the PMC project is built in a factory and site-work is concurrently being conducted. This reduces lag time that traditional on-site built work must sequence sequentially. The time saved with PMC is an opportunity for additional cost savings.

The Office of Legislative Oversight study demonstrated that change orders increased in the 17 cases they documented by $30.3 \%$. In two of the cases change orders more than doubled the construction time. 


\section{SCHEDULE COMPARISON}

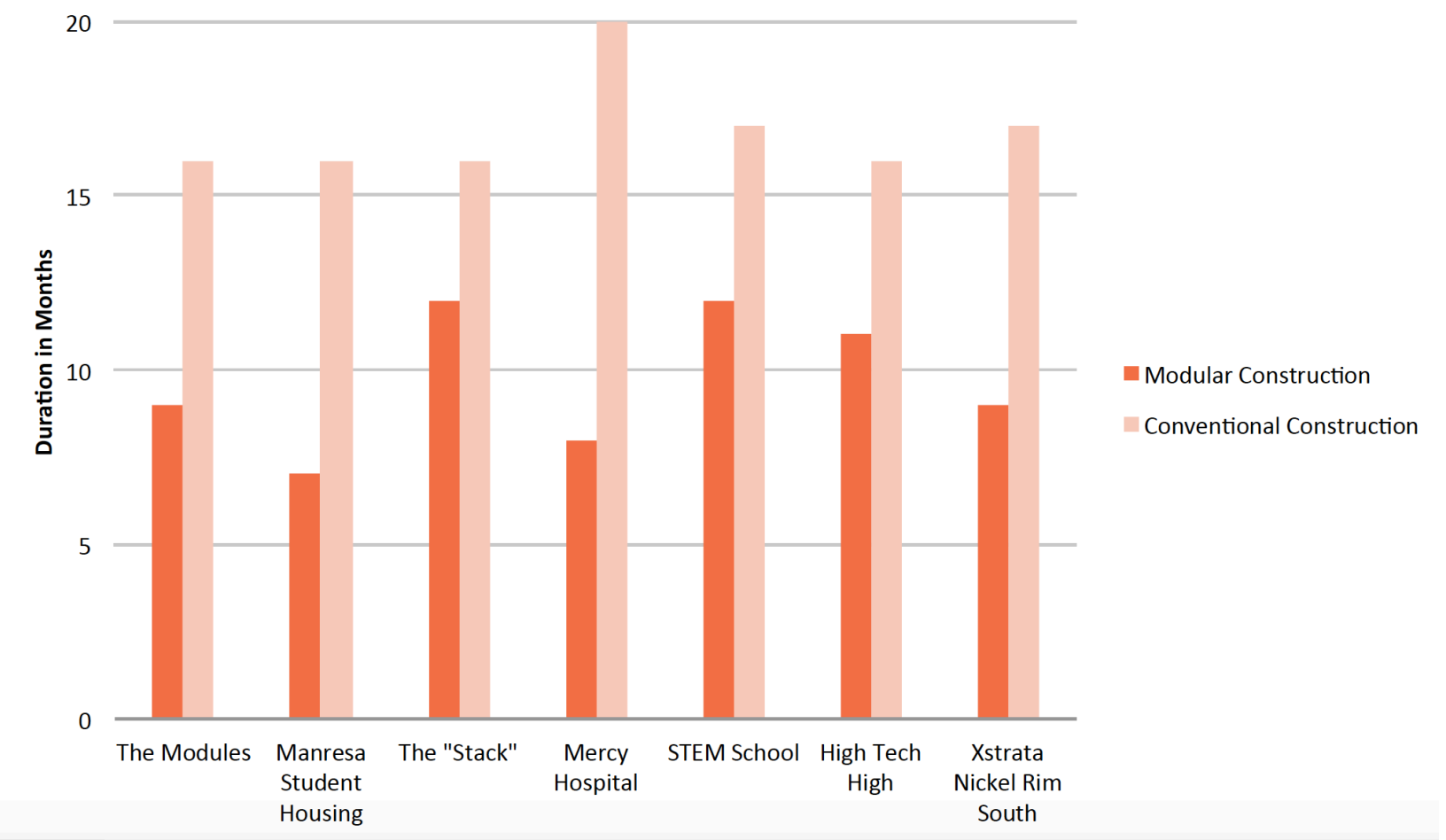

Figure 2. Schedule comparison between PMC projects and benchmark projects.

\section{Return on Investment}

Using PMC, the cases in this study reduced their construction time by and average of $42 \%$. To put this reduction of time in terms of cost benefit, a return on investment (ROI) method was developed to account for time savings. The ROI leveraged three discrete building type proformas from different developers: retail, office, and charter school buildings respectively. The developer data was assessed using a schedule improvement of $25 \%$ and $50 \%$ reduction from the actual schedule. This evaluation did not include the financial benefit of early return on operational business such as sales, or social/environmental impacts. It was a construction duration initial cost benefit analysis only, including lease rates.

The pro-formas include four sections:

- the analysis of the total build, the built time reduced by $25 \%$ and then $50 \%$;

- the cost of construction;

- the cost of the construction loan; and

- the generated income.

Market rate numbers for the ROI were based from the Newmark Grubb Acres 2014 Year End Report. The rental income numbers are based on the presumption that the building will be $100 \%$ occupied reflecting the higher possible opportunity for income. The pro-formas show two areas 
where there is an opportunity to save in cost using PMC. These areas include the cost of construction loan and the money generated during the time saved.

Retail

- The retail space at 25\% reduction shows a $\$ 5,187$ in saved interest, and $\$ 29,333$ generated in rental income for an effective gross income of $\$ 34,520$.

- At 50\% schedule reduction, \$10,350 was saved in construction loan interest and \$58,666 generate in rental income for and effective gross income of $\$ 69,017$. (Fig.3)

\section{Office}

- The office space pro-forma shows a construction interest savings of \$52,214 and a generated rental income of $\$ 292,333$ for an effective gross income of $\$ 345,547$ at $25 \%$ schedule reduction.

- At $50 \%$, the effective gross income is $\$ 518,147$. (Fig.4)

\section{Charter School}

- $\$ 29,821$ was saved in construction interest with a $25 \%$ schedule reduction. $\$ 134,029$ was generated in rental income for an effective gross income of $\$ 1623,851$.

- There would be a construction interest savings of $\$ 74,244$ with a $50 \%$ reduction. A general rental income of $\$ 335,074$ for an effective gross income of $\$ 409,318$. (Fig. 5)

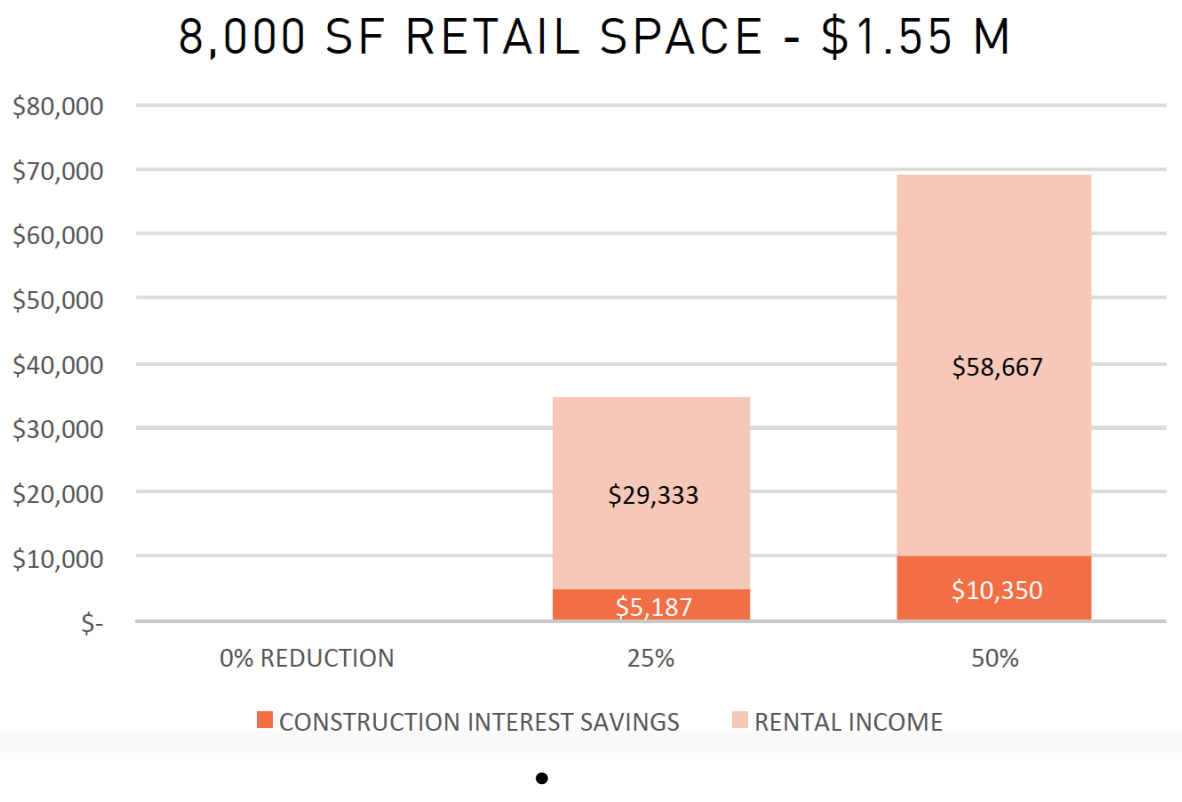

Figure 3. ROI for an $8,000 \mathrm{SF}$ retail space. 


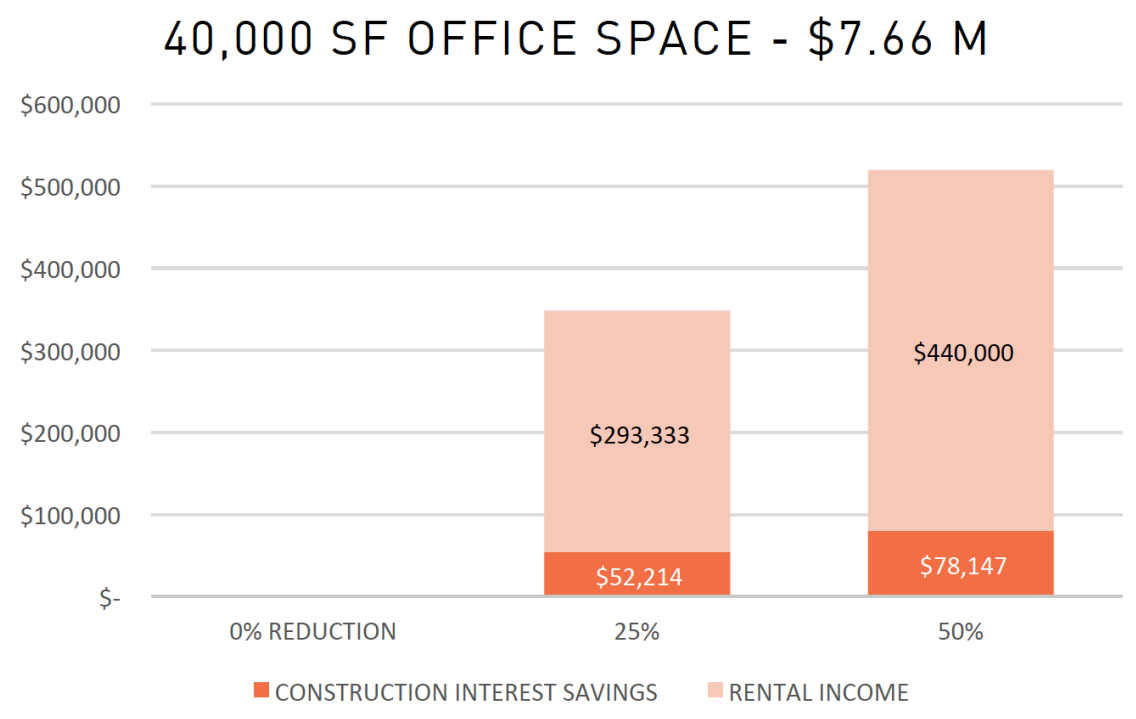

Figure 4. ROI for a 40,000 SF office space.

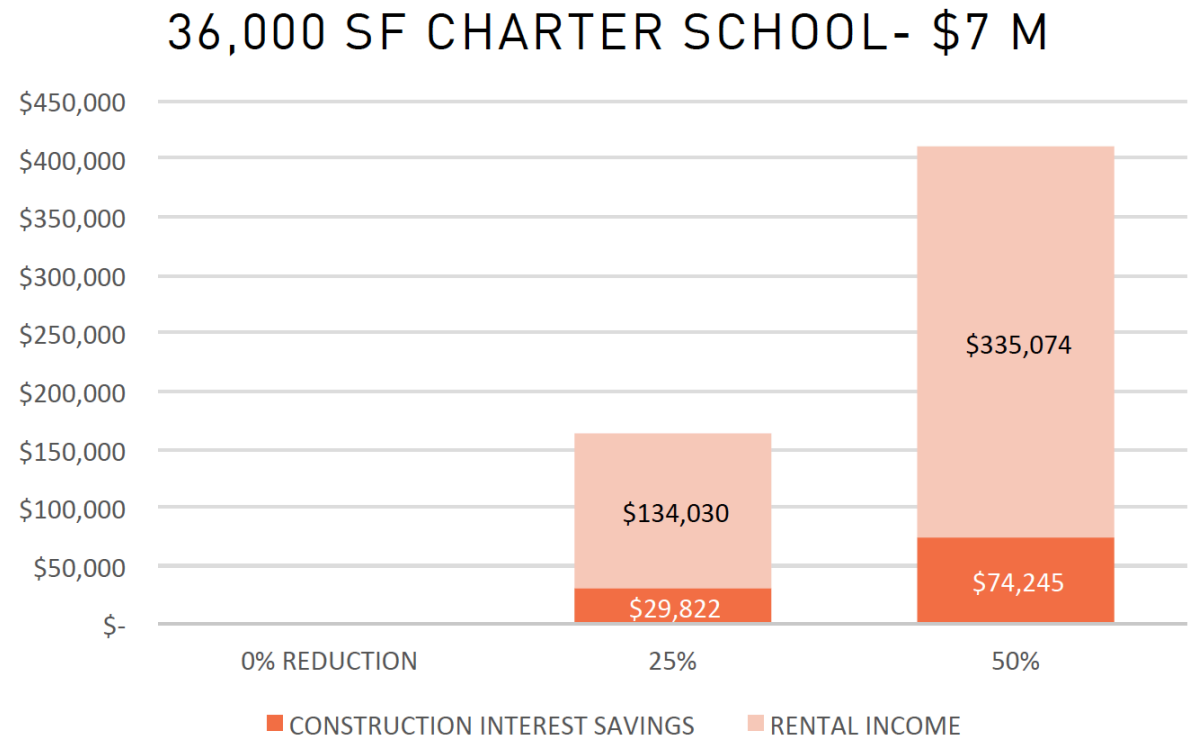

Figure 5. ROI for a 36,000 SF charter school.

The average cost savings for $25 \%$ schedule reduction across the three pro-formas is $\$ 5.81$ / SF in total construction cost. The average cost savings for $50 \%$ schedule reduction across the three pro-formas is $\$ 10.93$ / SF in total construction cost. 


\section{CONCLUSION}

The results from these case studies and comparative analysis of traditional stick built projects demonstrates that PMC offers:

- Cost reduction of $11 \%$;

- Schedule reduction of $42 \%$; and

- Return on investment of $\$ 5.81$ / SF for $25 \%$ reduced schedule and $\$ 10.93$ / SF for $50 \%$ reduced schedule.

After the economic downturn of 2008, the demand of construction and the supply of that construction followed suit. Construction demand is high again yet the supply to meet that demand has stayed down and cannot meet its requests. This presents a gap where modular construction can take advantage due to its lower labor requirements. The time is right for permanent modular construction.

\section{ACKNOWLEDGEMENTS}

This study was funded by an industry consortium including: Modular Building Institute Education Foundation and Canadian Foundation, Whiting Turner, Association of General Contractors, PCL Constructors, American Institute of Steel Construction, Triumph Modular. Modular Building Institute members and the National Institute of Building Sciences, Off-site Construction Council provided peer review.

\section{REFERENCES}

Cumming Corporation Internal Economic and Market Report.

David Bacon Wage Rates (2014).

Modular Building Institute. Improving Construction Efficiency and Productivity with Modular Construction. Accessed April 27, 2015. http://www.modular.org/marketing/documents/Whitepaper_ImprovingConstructionEfficiency.pd f and Modular Building Institute Website. Accessed April 17, 2015.

http://www.modular.org/HtmlPage.aspx?name=architects

Newmark Grubb Acres. (2014) 2014 Year End Utah/Mountain West Market Report. http://www.ngacres.com/public/uploads/1/2015/1/newmark_yearend.pdf.

Office of Legislative Oversight. (2014). "Change Orders in County Construction Projects." http://www.montgomerycountymd.gov/council/Resources/Files/agenda/cm/2014/140403/2014 0403_GO1.pdf.

RS Means Geographic Indices (2014).

RS Means Standard Hourly Rates for the Construction Industry (2014).

Smith, R.E. (2011) Prefab Architecture: a guide to modular design and construction. Chapter 3 Principles. John Wiley \& Sons Inc. Hoboken, NJ. 